\title{
Strategi WOW (Wide Open Wonder) Untuk Meningkatkan Keaktifan dan Prestasi Matematika Siswa (Penelitian Tindakan Kelas pada Siswa Kelas VII C SMPN 4 Geyer Grobogan pada 2014/2015)
}

\author{
Ali Rohmad ${ }^{1}$ dan Iwan Kuswidi ${ }^{2}$ \\ ${ }^{1}$ Guru Matematika SMPN 4 Geyer, Jl. Banyu Urip-suru, Geyer, Grobogan, Jawa Tengah, Indonesia \\ 2 Program Studi Pendidikan Matematika, Fakultas Sains dan Teknologi, Universitas Islam Negeri \\ Sunan Kalijaga Yogyakarta, Jl. Marsda Adisucipto Yogyakarta 55281
}

Korespondensi ditujukan kepada Iwan Kuswidi; Email: e_widy@yahoo.com

\begin{abstract}
Abstrak
Penelitian ini dilatarbelakangi oleh masih rendahnya partisipasi keaktifan dan prestasi siswa kelas VII C SMP Negeri 4 Geyer Grobogan Jawa Tengah dalam pembelajaran matematika. Hal tersebut berdasarkan studi awal yang menemukan bahwa siswa yang aktif baru 23,57\% dari keseluruhan siswa dan rata-rata prestasi matematika hanya 66,07. Dengan menerapkan penelitian tindakan kelas dan dengan menggunakan strategi Wide Open Wonder (WOW) berhasil meningkatkan keaktifan dan prestasi matematika siswa. Penelitian ini dilaksanakan pada tahun pelajaran 2014/2015 terhadap 28 siswa kelas VII C SMP Negeri 4 Geyer Grobogan Jawa Tengah yang terlaksana sebanyak 2 siklus. Adapun teknik pengumpulan data dilakukan dengan observasi dan tes. Keberhasilan penelitian ini yaitu dapat meningkatkan keaktifan siswa hingga mencapai 58,57\% dan meningkatkan rata-rata nilai prestasi matematika mencapai 75,36 serta sebanyak $85,71 \%$ siswa telah berhasil melampaui kriteria ketuntasan minimal (KKM).
\end{abstract}

Kata Kunci: wide open wonder; keaktifan; prestasi matematika.

\begin{abstract}
This research is motivated by the low participation of liveliness and student achievement of class VII C SMP Negeri 4 Geyer Grobogan Central Java in mathematics. It is based on a preliminary study found that students who are active just $23.57 \%$ of all students and an average of only 66.07 math achievement. By applying classroom action research and using strategies Wide Open Wonder (WOW) managed to enhance the activity and student mathematics achievement. The research was conducted in the academic year 2014/2015 to 28 students of class VII C SMP Negeri 4 Geyer Grobogan Central Java has been completed by 2 cycles. The data collection techniques by observation and tests. The success of this research is to increase the activity of students up to $58.57 \%$ and to increase the average value of math achievement reached 75.36 and as high as $85.71 \%$ of the students had already exceeded the minimum completeness criteria (KKM).
\end{abstract}

Keywords: wide-open wonder; the activity; mathematics achievement.

\section{Pendahuluan}

Salah satu tujuan pembelajaran matematika dalam kurikulum 2013 menurut permendikbud nomor 58 tahun $2014^{[2]}$ adalah untuk membekali peserta didik dengan kemampuan berpikir logis, analitis, sistematis, kritis, inovatif dan kreatif, serta kemampuan bekerjasama. Kompetensi tersebut diperlukan agar peserta didik dapat memiliki kemampuan memperoleh, mengelola, dan memanfaatkan informasi untuk bertahan hidup pada keadaan yang selalu berubah, tidak pasti, dan kompetitif.

Kemampuan-kemampuan tersebut akan dapat diperoleh dengan keterlibatan siswa secara aktif dan sukarela dalam proses pembelajaran. Dengan keterlibatan siswa dalam pembelajaran maka akan terasah 
dengan baik kemampuannya, karena siswa tertuntut berpikir kritis ketika berdiskusi, harus menganalisis fakta ketika menjawab pertanyaan dan harus kreatif-analitis ketika dituntut untuk bertanya.

Disamping keterlibatan secara aktif, salah satu indikator keberhasilan pembelajaran matematika adalah dengan dikuasainya materi matematika yang terlihat dari bagusnya hasil ulangan dan tes harian serta kemampuan dalam menjawab soal-soal matematika dalam proses pembelajaran dan latihan. Kemampuan penguasaan (prestasi) matematika ini juga akan mendukung kemampuan berpikir logis, sistematis dan analitis, karena untuk mampu menjawab persoalan matematika memang diperlukan kemampuan tersebut.

Sesuai hasil studi awal dan pengamatan keseharian, keaktifan dan prestasi matematika siswa kelas VII C SMPN 4 Geyer menunjukkan hasil yang kurang dan masih perlu untuk ditingkatkan. Hal ini terlihat dari rata-rata persentase siswa yang aktif hanya $23,57 \%$, baik keaktifan dalam mengerjakan tugas, menjawab pertanyaan guru, mengajukan pertanyaan, menanggapi jawaban siswa dan berdiskusi. Begitujuga dengan prestasi matematika, rata-rata nilai matematika yang diperoleh baru 66,07 dari nilai maksimal 100 dan yang mencapai kriteria ketuntasan minimal (KKM) baru 64,29\% dari keseluruhan siswa.

Banyak strategi dan metode pembelajaran yang dapat dilakukan untuk melatih keaktifan dan prestasi siswa. Salah satunya adalah dengan metode pembelajaran Quantum Teaching yang dikembangkan oleh Bobbi DePorter, Mark Reardon, dan Sarah Singger Nourie [3]. Salah satu strategi yang dikembangkan pada pembelajaran Quantum Teaching adalah strategi Wide Open Wonder (WOW) yang arti frasanya adalah ketakjuban yang luar biasa. Pada strategi WOW ini menyajikan materi pembelajaran yang menarik (menakjubkan) di hadapan siswa. Oleh karena itu pada strategi ini diperlukan adanya usaha guru untuk menghadirkan setiap materi matematika di hadapan siswa sebagai sesuatu yang menakjubkan. Beberapa hal yang dapat dilakukan guru adalah dengan mengajukan pertanyaan terbuka yang kreatif, yang mengupas lebih dari sekedar jawaban benar, dan menjawab pertanyaan dengan lebih banyak pertanyaan, dan juga bisa dengan menghadirkan benda-benda nyata yang mungkin sudah sering dijumpai siswa tetapi ada sisi yang menakjubkan yang belum siswa pahami dan memiliki hubungan dengan materi yang akan disampaikan oleh guru ${ }^{[3]}$.

Penerapan strategi $W O W$ dengan baik akan menjadikan siswa secara sendirinya berperan serta sacara aktif dalam proses pembelajaran karena siswa belajar diawali dengan katakjuban, penjelajahan dan pertanyaan yang merupakan peran sejati siswa dan belajar. Siswa merasa ada sesuatu yang harus mereka ketahui dan dalami, sehingga materi yang mereka pelajari akan lebih bermakna dan tertanam dalam diri siswa secara baik dan pada akhirnya dapat meningkatkan penguasaan matematika siswa.

\section{Rumusan Masalah}

Adapun rumusan masalah dalam penelitian ini adalah: Apakah penerapan strategi WOW (Wide Open Wonder) dapat meningkatkan keaktifan dan prestasi matematika siswa kelas VII C SMPN 4 Geyer?

\section{Tujuan Penelitian}

Tujuan pelaksanaan penelitian ini adalah untuk meningkatkan keaktifan dan prestasi matematika siswa kelas VII C SMPN 4 Geyer. Keaktifan yang dimaksud adalah keterlibatan siswa dalam mengerjakan tugas/latihan soal, merespon pertanyaan guru, mengajukan pertanyaan dan mengemukakan pendapat, menanggapi pertanyaan/jawaban siswa lain, dan keaktifan dalam diskusi kelompok. Sedangkan prestasi matematika adalah kemampuan penguasaan matematika yang dilihat dari hasil nilai tes matematika.

\section{Landasan Teori}

\section{Strategi WOW}

Strategi WOW atau ketakjuban besar adalah salah satu strategi dalam Quantum Teaching yang dikembangkan oleh Bobbi Deporter, Mark Reardon, dan Sarah Singger Nourie. Beberapa ahli menyebutnya dengan istilah yang berbeda-beda, seperti Melvin L. Silberman ${ }^{[4]}$ menyebut strategi ini 
dengan strategi pikiran yang penuh tanya selalu ingin mengetahui . Sedang Hisyam Zaini dkk. ${ }^{[5]}$ menyebutnya dengan strategi Inquiring Minds Want to Know .

Strategi ini dikembangkan berdasarkan karakteristik perkembangan anak sejak mereka bayi hingga rata-rata mereka masuk sekolah formal. Menurut Bobbi Deporter ${ }^{[3]}$, bayi adalah mesin takjub yang bagi mereka setiap benda yang mereka jumpai adalah sebagai sesuatu yang menakjubkan dan harus mereka jelajahi serta pahami setiap jengkalnya dengan cara mereka sendiri, entah dengan memasukannya ke mulut, menggigit, menjatuhkan, mengocak-ocak dan sebagainya tanpa mengenal lelah.

Melvin L. Silberman ${ }^{[4]}$ dan Hisyam Zaini dkk ${ }^{[5]}$ merumuskan langkah-langkah/prosedur strategi WOW sebagai berikut.

1. Ajukan pertanyaan yang njelimet untuk menstimulasi keingin tahuan tentang materi yang akan dipelajari. Pertanyaan tersebut haruslah merupakan pertanyaan yang menantang tetapi diperkirakan ada siswa yang mengetahui

2. Doronglah siswa untuk berpikir dan membuat dugaan umum. Gunakan frase semisal coba tebak atau coba jawab

3. Jangan buru-buru memberikan tanggapan. Tampung dulu semua tanggapan siswa. Ciptakan penasaran tentang jawaban yang sesungguhnya.

4. Gunakan pertanyaan itu untuk mengarahkan siswa kepada apa yang hendak diajarkan. Sertakan jawaban atas pertanyaan tersebut dalam penyajian materi. Dan diusahakan siswa lebih menarik perhatian dari pada biasanya.

Lebih lanjut Melvin L. Silberman ${ }^{[4]}$ menjelaskan sebagai variasi strategi ini dapat dilakukan secara kolektif dalam membuat dugaan, atau bisa juga dengan cara mengenalkan materi yang akan diajarkan seperti mengiklankan sebuah film yang akan segera ditayangkan.

\section{Keaktifan Siswa}

Aktif berarti selalu berusaha, bekerja, atau belajar dengan sungguh-sungguh supaya mendapat kemajuan atau prestasi yang gemilang sedangkan keaktifan diartikan sebagai aktivitas kegiatan kesibukan. ${ }^{[6]}$ Dengan demikian keaktifan siswa diartikan sebagai keadaan siswa yang aktif dalam mengikuti kegiatan pembelajaran.

Paul B. Diederich membuat suatu daftar yang berisikan 177 macam aktifitas siswa yang dapat digolongkan menjadi delapan, yang selanjutnya dikutip oleh S. Nasution ${ }^{[7]}$ sebagai berikut:

1. Visual activities yaitu membaca, memperhatikan: gambar, demonstrasi, percobaan, pekerjaan orang lain dan sebagainya.

2. Oral activities yaitu menyatakan, merumuskan, bertanya, memberi saran, mengeluarkan pendapat, mengadakan: wawancara, diskusi, interupsi, dan sebagainya.

3. Listening activities yaitu mendengarkan: uraian, percakapan, diskusi, music, pidato, dan lain sebagainya.

4. Writing activities yaitu menulis: cerita, karangan, laporan, tes, angket, menyalin dan sebagainya.

5. Drawing activities yaitu melakukan percobaan, membuat konstruksi, model, mereparasi, bermain, berkebun, memelihara binatang, dan sebagainya.

6. Motor activities yaitu melakukan percobaan, membuat konstruksi, model, mereparasi, bermain, berkebun, memelihara binatang, dan sebagainya.

7. Mental activities yaitu menanggap, mengingat, memecahkan soal, menganalisis, melihat hubungan, mengambil keputusan, dan sebagainya.

8. Emotional activities yaitu menaruh minat, merasa: bosan, gembira, berani, tenang, gugup, dan sebagainya.

Selain uraian di atas, menurut Melvin L. Silberman ${ }^{[4]}$ agar belajar lebih aktif dan paham maka siswa harus mengerjakan tugas-tugas yang mengharuskan siswa bekerja menggunakan otak, mengkaji gagasan, memecahkan masalah dan menerapkan apa yang dipelajari.

Keaktifan siswa dapat juga dilatih dengan teknik pertanyaan, baik yang berkaitan dengan tuntutan menjawab pertanyaan maupun tuntutan untuk mengajukan pertanyaan. Hal ini senada dengan pendapat Hasibuan (1988) dalam konteks pembelajaran dan sudut pandang teori belajar, pertanyaan merupakan 
suatu stimulus yang mendorong anak untuk berpikir dan belajar sehingga anak akan lebih mudah menguasai materi atau konsep yang diberikan dan kemampuan berpikir siswa akan lebih berkembang.

Keaktifan juga dapat dilatihkan dengan cara diskusi, yaitu mengelompokkan siswa yang memungkinkan untuk saling tukar pendapat terhadap suatu permasalahan yang diajukan. Dengan pembelajaran secara berkelompok dimungkinkan siswa secara aktif memadukan pemahaman mereka pada materi yang sedang dipelajari sehingga pemahaman siswa lebih bermakna dibandingkan dengan belajar secara individual. Seperti yang dijelaskan oleh Melvin L. Silberman ${ }^{[4]}$ tentang penelitian yang dilakukan oleh Ruhl, Hughes, dan Schloss dengan meminta siswa untuk berdiskusi dengan teman sebangkunya tentang apa yang dijelaskan oleh guru pada beberapa jeda waktu yang disediakan selama pembelajaran berlangsung dapat meningkatkan hasil belajar siswa dengan selisih dua angka lebih baik dengan siswa yang tidak melakukan diskusi.

Dari uraian di atas, maka keaktifan siswa dapat dirangkum dalam suatu aktifitas yang dilakukan siswa yang meliputi keaktifan dalam mengerjakan tugas, menjawab pertanyaan guru, mengajukan pertanyaan, menanggapi jawaban siswa dan berdiskusi.

\section{Prestasi Matematika}

Menurut Benyamin Bloom, menyebutkan bahwa ada tiga kawasan hasil pembelajaran, yaitu kognitif, afektif dan psikomotor, hal ini sesuai kutipan M. Surya ${ }^{[8]}$, sedang menurut Gagne, hasil belajar adalah keluaran dari pemrosesan informasi yang berupa kecakapan manusia yang terdiri atas: informasi verbal, kecakapan intelektual, strategi kognitif, sikap dan kecakapan motorik.

Pandangan diatas selaras dengan tujuan pembelajaran matematika menurut standar isi kurikulum nasional yaitu peserta didik diharapkan memiliki kemampuan sebagai berikut:

1. Memahami konsep matematika, menjelaskan keterkaitan antar konsep dan mengaplikasikan konsep atau algoritma, secara luwes, akurat, efisien dan tepat, dalam pemecahan masalah.

2. Menggunakan penalaran pada pola dan sifat, melakukan manipulasi matematika dalam membuat generalisasi, menyusun bukti, atau menjelaskan gagasan dan pernyataan matematika.

3. Memecahkan masalah yang meliputi kemampuan memahami masalah, merancang model matematika, menyelesaikan model dan menafsirkan solusi yang diperoleh.

4. Mengomunikasikan gagasan dengan simbol, tabel, diagram atau media lain untuk memperjelas keadaan atau masalah.

5. Memiliki sikap menghargai kegunaan matematika dalam kehidupan, yaitu memiliki rasa ingin tahu, perhatian dan minat dalam mempelajari matematika, serta sikap ulet dan percaya diri dalam pemecahan masalah.

Adapun yang dimaksud prestasi matematika dalam penelitian ini adalah kemampuan kognitif penguasaan pemahaman matematika dalam memecahkan permasalahan matematika dan cara mengkomunikasikannya dalam bentuk tulisan (jawaban) yang diukur dengan menggunakan tes matematika.

\section{Metode Penelitian}

Penelitian ini dilaksanakan di SMPN 4 Geyer, Kabupaten Grobogan pada semester gasal tahun pelajaran 2014/2015. Adapun subjek penelitiannya adalah 28 siswa kelas VII C dengan rincian 16 laki-laki dan 12 perempuan. Penelitian ini dilakukan dengan desain penelitian tindakan kelas (class action research) Kemmis dan Mc Taggart ${ }^{[1]}$ yang terlaksana hingga dua siklus yang pada setiap siklusnya dilalui prosedur: (1) perencanaan (planning), (2) pelaksanaan tindakan (action), (3) pengamatan (observation), (4) refleksi (reflection). Instrumen pengumpulan data yang digunakan adalah lembar observasi dan tes kemampuan matematika. Pengamatan dilakukan pada setiap pembelajaran setiap siklus, sedang tes matematika dilaksanakan pada akhir setiap siklus. Kemudian data dianalisis dengan menggunakan analisis deskriptif. 


\section{Hasil dan Pembahasan}

Dari penelitian yang dilaksanakan di SMPN 4 Geyer pada siswa kelas VII C selama satu semester, setelah diterapkan strategi WOW diperoleh peningkatan yang signifikan, baik dalam peningkatan keaktifan siswa maupun peningkatan prestasi matematika siswa.

Pada keaktifan siswa, dari awal sebelum diterapkan strategi WOW siswa yang aktif rata-rata pada 5 aktifitas siswa hanyalah $23,5 \%$ dari keseluruhan siswa. Dan meningkat menjadi 49,29\% setelah siklus pertama dan meningkat lagi menjadi 58,57\% setelah siklus kedua. Dari kelima aktifitas siswa, yang paling tinggi peningkatannya adalah pada keaktifan dalam menjawab pertanyaan guru, yaitu jumlah siswa yang aktif bertambah $42,86 \%$ dari keseluruhan siswa. Aktifitas yang meningkat tinggi selain itu adalah aktifitas mendiskusikan materi dengan siswa lain, peningkatannya yaitu 42,85\%, artinya siswa yang aktif berdiskusi bertambah $42,85 \%$. Lebih lengkap penjelasan ini terlihat pada tabel 1.

Tabel 1 Persentase perkembangan keaktifan siswa setelah mendapatkan strategi WOW.

\begin{tabular}{llrrr}
\hline No & \multicolumn{1}{c}{ Keaktifan siswa } & Kondisi Awal & Setelah Siklus I & Setelah Siklus II \\
\hline 1 & Mengerjakan tugas/latihan & $35,71 \%$ & $67,86 \%$ & $71,43 \%$ \\
2 & Menjawab pertanyaan guru & $21,43 \%$ & $57,14 \%$ & $64,29 \%$ \\
3 & Mengajukan pertanyaan & $10,71 \%$ & $28,57 \%$ & $35,71 \%$ \\
4 & Menanggapi jawaban siswa lain & $7,14 \%$ & $21,43 \%$ & $35,71 \%$ \\
5 & Mendiskusikan materi dengan siswa lain & $42,86 \%$ & $71,43 \%$ & $85.71 \%$ \\
\hline \multicolumn{2}{c}{ Rata-rata } & $23,57 \%$ & $49,29 \%$ & $58,57 \%$ \\
\hline
\end{tabular}

Adapun pada prestasi matematika, rata-rata awal yang dicapai baru 66,07 dari nilai maksimal 100, dan meningkat menjadi 70 setelah sikluas pertama dan meningkat lagi menjadi 75,36 setelah siklus kedua. Persentase jumlah siswa yang masuk kriteria baik dan sangat baik, pada awal baru $78,57 \%$ dan meningkat menjadi $85,71 \%$ setelah siklus pertama dan meningkat lagi menjadi $96,43 \%$ setelah siklus kedua. Tentang kondisi peningkatan prestasi matematika, lebih menyeluruh terlihat pada tabel 2.

Tabel 2 Perkembangan prestasi matematika siswa setelah mendapatkan strategi WOW.

\begin{tabular}{llrrr}
\hline No & Rentang Nilai & Kondisi Awal & Setelah Siklus I & Setelah Siklus II \\
\hline 1 & Sangat baik & $7,14 \%$ & $10,71 \%$ & $14,29 \%$ \\
& $(86-100)$ & $(2)$ & $(3)$ & $(4)$ \\
2 & Baik & $71,43 \%$ & $75,00 \%$ & $82,14 \%$ \\
& $(61-85)$ & $(20)$ & $(21)$ & $(23)$ \\
3 & Cukup & $14,29 \%$ & $10,71 \%$ & $3,57 \%$ \\
& $(36-60)$ & $(4)$ & $(3)$ & $(1)$ \\
4 & Kurang & $7,14 \%$ & $3,57 \%$ & $0,00 \%$ \\
& $(0-35)$ & $(2)$ & $(1)$ & $(0)$ \\
\hline & Jumlah & $100 \%$ & $100 \%$ & $100 \%$ \\
& Rata-rata & 66,07 & 70,00 & 75,36 \\
\hline
\end{tabular}

Adapun kriteria ketuntasan minimal (KKM) yang dibatasi nilai diatas 67, pada kondisi baru 64,29\% siswa yang mencapainya, dan meningkat menjadi $75 \%$ setelah siklus pertama dan meningkat lagi menjadi $85,71 \%$ setelah siklus kedua. Gambaran lebih utuh tentang pencapaian KKM terlihat pada tabel 3 berikut: 
Tabel 3 Perkembangan ketuntasan belajar siswa setelah mendapatkan strategi WOW.

\begin{tabular}{lrrr}
\hline $\begin{array}{l}\text { Ketuntasan } \\
\text { KKM=67 }\end{array}$ & Kondisi Awal & Setelah Siklus I & Setelah Siklus II \\
\hline $\begin{array}{l}\text { Tuntas } \\
(\text { KKM) }\end{array}$ & $64,29 \%$ & $75 \%$ & $85,71 \%$ \\
$\begin{array}{l}\text { Belum Tuntas } \\
(<\text { KKM) }\end{array}$ & $(18)$ & $(21)$ & $(24)$ \\
\multicolumn{1}{r}{ Jumlah } & $35,71 \%$ & $25 \%$ & $(7)$ \\
\hline
\end{tabular}

\section{Kesimpulan}

Dari hasil penelitian ini, terlihat bahwa keaktifan siswa dan prestasi matematika siswa dapat ditingkatkan dengan menerapkan strategi wide open wonder. Rata-rata jumlah siswa yang aktif meningkat $35 \%$ dan rata-rata nilai prestasi matematika siswa meningkat 9,28. Hal ini membuktikan bahwa penerapan strategi WOW efektif dalam meningkatkan keaktifan dan prestasi matematika siswa.

\section{Referensi}

[1] Desai, Amrita. 2007. Increasing Integration of Technology in Classrooms Throught Enhanced Teacher Knowledge and Efficacy. New Jersey: ProQuest.

[2] Mendikbud. 2014. Permendikbud Nomor 58 tahun 2014 Tentang Kurikulum 2013 Sekolah Menengah Pertama / Madrasah Tsanawiyah. Jakarta: Kemdikbud.

[3] DePorter, Bobbi dkk. 1999. Quantum Teaching: Orchestrating Student Success. Boston: Allyn and Bacon.

[4] Silberman, Melvin L. 2006. Active Learning 101 Cara Belajar Siswa Aktif (terj). Bandung: Nusa Media.

[5] Zaini, Hisyam \& Bermawi M. 2004. Strategi Pembelajaran Aktif. Yogyakarta: CTSD.

[6] Salim, Peter \& Yenny S. 1991. Kamus Bahasa Indonesia Kontemporer. Jakarta: Modern English Press.

[7] Nasution, S. 1995. Didaktik Asas Mengajar. Jakarta: Bumi Aksara.

[8] Surya, Muhammad. 2003. Psikologi Pembelajaran dan Pengajaran. Jakarta: CV Mahaputra Adidaya. 